\title{
COMPARATIVE STUDY OF FRACTURES OF PELVI-ACETABULUM INVOLVING ANTERIOR WALL AND ANTERIOR COLUMN BETWEEN CONSERVATIVE AND OPERATIVE PROCEDURE
}

\author{
Rajiv Roy1, Subhasis Ranjan Mitra²
}

1Associate Professor, Department of Orthopaedic Surgery, Calcutta National Medical College, Kolkata, West Bengal, India.

${ }^{2}$ Associate Professor, Department of Orthopaedic Surgery, Calcutta National Medical College, Kolkata, West Bengal, India.

\begin{tabular}{l}
\hline ABSTRACT \\
BACKGROUND \\
acetabular fracture treatment depends on congruency of the hip joint, along with stable fixation of the acetabulum. Open reduction \\
and internal fixation (ORIF) is still the best treatment for acetabular fractures, in an ideal set-up. Minimally displaced fractures may \\
be treated non-operatively with good results.
\end{tabular}

\section{METHODS}

Twenty-two patients were treated at our Institute from July 2015 to January 2017, of whom 12 patients were treated by operative means (open reduction internal fixation) and rest 10 were treated conservatively, by below knee traction. Of the ten patients treated conservatively, 1 patient was lost in follow-up. ORIF in the 12 patients treated surgically was done through anterior Ilioinguinal approach and fixed with appropriate reconstruction plates or buttress plates.

\section{RESULTS}

Assessment was done by radiological methods as described by Matta. J and functional outcomes detailed by Harris hip score, and Merle d'Aubigne and Postel. In the study we observed that the mean age of incidence amongst patients who were treated by ORIF, was 35.6 yrs. \pm 4.14 , and that for the other group treated conservatively was 48.33 yrs. \pm 10.74 , with a significant $p$ value of 0.001 (Table 2). Males were affected 3.2 times more than females, $p=0.35$ (Table 2), not so statistically significant. 9 patients treated conservatively who were followed up had good to fair outcomes radiologically (Table 1). Of the twelve patients, who underwent surgery (ORIF), 8 had excellent radiological outcome and rest 4 had good outcome (Table 1). Patients who underwent surgery had an average HHS of $88.42 \% \pm 3.87 \%$ (good to excellent), and those treated conservatively had a mean HHS of $79.67 \pm 4.5$. The mean MDBP scores were $17.08 \pm 1.38$ and $13.89 \pm 1.54$, for the operated (ORIF) and conservatively treated groups respectively. In this study we observed a statistically significant difference, between the operated group and conservative group, in both HHS and MDBP, $p<0.0001$ (Table 3). In the ORIF group, the congruous reduction patients had a mean HHS of $89.5 \pm 3.24$, and in the patients with incongruous reduction mean HHS was 83.0 \pm 0 , with a significant p value of 0.02 (Table 4). In the group of patients treated conservatively the mean HHS for congruous reduction and incongruous reduction was $82.4 \pm 2.70$ and $76.25 \pm 4.03$ respectively, with a significant $\mathrm{p}$ value of 0.03 (Table 4). In the ORIF group, the congruous reduction patients had a mean MDBP of 17.5 \pm 1.08 , and in the patients with incongruous reduction mean MDBP was $15.0 \pm 0$, with a significant p value of 0.01 (Table 4 ). In the group of patients treated conservatively, the mean MDBP for congruous reduction and incongruous reduction was $14.8 \pm 1.30$ and $12.75 \pm 0.96$ respectively, with a significant $p$ value of 0.03 (Table 4 ).

\section{CONCLUSIONS}

Fractures which are minimally displaced may be treated conservatively, but displaced fractures were better managed by operative means.

\section{KEY WORDS}

Acetabulum, Fractures, Traction, Open Reduction and Internal Fixation (ORIF), Anterior Ilio-Inguinal Approach, Anterior Column, Reconstruction Plates, Harris Hip Score, Merle d'Aubigne and Postel Score

HOW TO CITE THIS ARTICLE: Roy R, Mitra SR. Comparative study of fractures of pelvi-acetabulum involving anterior wall and anterior column between conservative and operative procedure. J. Evolution Med. Dent. Sci. 2019;8(24):1935-1939, DOI: $10.14260 /$ jemds/2019/425

\section{BACKGROUND}

It is widely accepted that the most important principle of acetabular fracture treatment is anatomical restoration of the acetabular surface, particularly the weight bearing zone and stable internal fixation, resulting in a congruent hip 1,2 , i.e. the head of the femur is well covered and protected by the

'Financial or Other Competing Interest': None.

Submission 07-11-2018, Peer Review 26-05-2019,

Acceptance 01-06-2019, Published 17-06-2019.

Corresponding Author:

Subhasis Ranjan Mitra,

\#16B, Dr. Sundari Mohan Avenue,

Kolkata-700014, West Bengal, India.

E-mail: subhasis.mitra1962@gmail.com

DOI: $10.14260 /$ jemds $/ 2019 / 425$

\section{(c) $(i) \ominus$}

acetabular wall, particularly the weight bearing portion of the head. Open reduction and internal fixation (ORIF) is still the best treatment for displaced acetabular fractures. However, it is a specialized surgery and requires technical expertise and practice in addition to knowledge. To the average orthopaedic surgeons, bilateral below knee (Spad) surface traction or skeletal traction applied in the lower end of femur or upper end of tibia, is an alternative for minimally displaced fractures. The stability of the hip, the concentricity of the femoral head below the acetabular roof, and the condition of the acetabulum are the major factors influencing the outcome of non- operative treatment of the acetabulum fractures ${ }^{3}$. Fractures not involving the weight bearing dome have much better prognosis ${ }^{1}$, and can be treated conservatively. However displaced fractures, and those involving the weight bearing dome are better managed surgically. 


\section{METHODS}

This prospective study was conducted at the Department of Orthopaedic Surgery, Calcutta National Medical College, between July 2015 and January 2017, to compare the outcomes of the treatment of Acetabulum fractures by operative and conservative methods. Of the patients attending the emergency room and OPD with pelvi-acetabular fractures, study population was drawn from consecutive 22 patients, who gave informed consent and who met the inclusion and exclusion criteria. After routine investigations, including antero-posterior, inlet, outlet and Judet view skiagrams and Computerised Axial Tomograms. Twelve patients were operated and remaining 10 patients were treated conservatively, by below knee skeletal traction. Ethical clearance was obtained from the Institute's ethics committee.

Outcome was assessed by radiologic methods as described by Matta J.4 (Box 1) and functional methods as described by Harris Hip Score, 5 and Merle d'Aubigne and Postel $^{6}$ (Box -2).

\section{Inclusion Criteria}

1. Patients presenting within one week of incidence.

2. Fractures involving the anterior column of acetabulum.

3. Fractures of the Pelvic brim including pubic rami and ischium.

4. Fractures involving the sacrum and sacroiliac joint.

5. Patients within 20-70 years of age.

\section{Exclusion Criteria}

1. Fractures involving only posterior column or wall of acetabulum.

2. Protrusio acetabuli or central fracture dislocation also involving posterior wall or column of the acetabulum.

3. Patients with serious co-morbid pathologies, or associated long bone fractures of the lower limbs.

\section{Procedures Used in Conservative Treatment}

Only in minimally displaced anterior wall or column fractures, i.e. $<3 \mathrm{~mm}$ stepping we have used bilateral below knee skeletal tractions for 6 weeks. Following this traction period patients were encouraged to do hip and knee movements in sitting posture and supine positions for another six weeks. Bilateral axillary crutch assisted partial weight bearing was the next step, in the rehabilitation period. Meticulous nursing care was imperative to prevent pressure sores. Patients would be made to sit up in the bed to prevent hypostatic pneumonia. Lung physiotherapy including deep breathing exercises were advised. Static and dynamic knee exercises were encouraged as the pain waned. Anticoagulants were not administered in this series. Only 10 patients had been treated conservatively, but unfortunately one patient was lost in follow - up.

\section{Procedures Used in Operative Treatment}

In the other 12 patients, we used the ilio-inguinal approach using three separate windows. The medial most retracting the spermatic cord and lymphatic venous plexus, the lateral most retracting the femoral vessels and nerves and the intermediate, retracting the iliopsoas. Reconstruction plates were bent and aligned along the curvature of the bone, fracture fragments reduced gently with bone spikes and fractures fixed rigidly. Occasionally buttressing of quadrilateral surface of the acetabulum, was done using buttress plates, or reconstruction plates.

\begin{tabular}{|c|c|c|c|}
\hline Grade & Osteophyte & Joint Space Narrowing & Sclerosis \\
\hline Excellent & None & Normal & None \\
\hline Good & Small & $>2 \mathrm{~mm}$ & Minimal \\
\hline Fair & Moderate & $<50 \%$ & Moderate \\
\hline Poor & Large & $>50 \%$ & $\begin{array}{c}\text { Severe With } \\
\text { Femoral Head } \\
\text { Collapse }\end{array}$ \\
\hline \multicolumn{3}{|c|}{ Box 1. Mata's Criteria } \\
\hline
\end{tabular}

\begin{tabular}{|c|c|c|c|}
\hline Score & Pain & $\begin{array}{c}\text { Hip Range Of } \\
\text { Motion }\end{array}$ & Walking Ability \\
\hline 0 & $\begin{array}{c}\text { Disabling pain } \\
\text { at rest }\end{array}$ & $\begin{array}{c}\text { Ankylosis in poor } \\
\text { position }\end{array}$ & $\begin{array}{c}\text { No walking } \\
\text { possible }\end{array}$ \\
\hline 1 & $\begin{array}{c}\text { Pain interfering with } \\
\text { sleep }\end{array}$ & $\begin{array}{c}\text { No movement, } \\
\text { slight deformity }\end{array}$ & $\begin{array}{c}\text { Only with } 2 \text { crutches } \\
\text { or frame }\end{array}$ \\
\hline 2 & $\begin{array}{c}\text { Pain that prevents } \\
\text { walking }\end{array}$ & Flexion $>40^{\circ}$ & $\begin{array}{c}\text { Minimal walking with } \\
\text { one cane }\end{array}$ \\
\hline 3 & $\begin{array}{c}\text { Pain tolerable with } \\
\text { limited activity }\end{array}$ & Flexion $40^{\circ}-60^{\circ}$ & $\begin{array}{c}\text { Walking for }<1 \text { hour } \\
\text { with one cane }\end{array}$ \\
\hline 4 & $\begin{array}{c}\text { Pain that disappears } \\
\text { with rest }\end{array}$ & Flexion $60^{\circ}-80^{\circ}$ & $\begin{array}{c}\text { Short walk without } \\
\text { cane but marked limp }\end{array}$ \\
\hline 5 & $\begin{array}{c}\text { Mild pain with } \\
\text { normal activity }\end{array}$ & $\begin{array}{c}\text { Flexion } 80^{\circ}-90^{\circ}+ \\
15^{\circ} \text { abduction }\end{array}$ & $\begin{array}{c}\text { Walks without cane } \\
\text { but noticeable limp }\end{array}$ \\
\hline \multicolumn{3}{|c|}{ Box 2 Merle d'Aubigne-Postel Scoring System } \\
\hline \multicolumn{4}{|c|}{} \\
\hline
\end{tabular}

\begin{tabular}{|c|c|c|}
\hline & Operative & Conservative \\
\hline Excellent & 8 & - \\
\hline Good & 4 & 5 \\
\hline Fair & - & 4 \\
\hline \multicolumn{3}{|c|}{ No poor outcome in any group } \\
\hline \multicolumn{2}{|c|}{ Table 1. Radiological Outcome as per Mata's Criteria } \\
\hline
\end{tabular}

\begin{tabular}{|c|c|c|c|c|}
\hline \multicolumn{2}{|c|}{ Demographics } & $\begin{array}{c}\text { Patients } \\
\text { Treated by } \\
\text { ORIF } \\
(n=12)\end{array}$ & $\begin{array}{l}\text { Patients Treated } \\
\text { by Conservative } \\
\text { Methods } \\
(n=9)\end{array}$ & $\mathbf{P}$ \\
\hline \multicolumn{2}{|c|}{ Age (mean \pm S.D.) yrs. } & $35.67 \pm 4.14$ & $48.33 \pm 10.74$ & $<0.0013$ \\
\hline \multirow{2}{*}{$\begin{array}{c}\text { Sex } \\
\text { No. (\%) } \\
\end{array}$} & Male & $10(83.33)$ & $6(66.67)$ & \multirow{2}{*}{$\begin{array}{l}0.35 \text { (Yates } \\
\text { correction) }\end{array}$} \\
\hline & Female & $2(16.67)$ & $3(33.33)$ & \\
\hline \multicolumn{5}{|c|}{ Table 2. Patient Demographics } \\
\hline
\end{tabular}

\begin{tabular}{|c|c|c|c|}
\hline $\begin{array}{c}\text { Methods of } \\
\text { Scoring }\end{array}$ & $\begin{array}{c}\text { Patients } \\
\text { Treated by } \\
\text { ORIF (n=12) } \\
\text { Mean } \pm \text { S.D. }\end{array}$ & $\begin{array}{c}\text { Patients Treated } \\
\text { Conservatively } \\
(\mathbf{n = 9 )} \\
\text { Mean } \pm \text { S.D. }\end{array}$ & P \\
\hline Harris' Hip Score (\%) & $88.42 \pm 3.87$ & $79.67 \pm 4.5$ & $<0.0001$ \\
\hline $\begin{array}{c}\text { Merle d'Aubigne-Postel } \\
\text { Score }\end{array}$ & $17.08 \pm 1.38$ & $13.89 \pm 1.54$ & $<0.0001$ \\
\hline \multicolumn{3}{|c|}{} \\
\hline
\end{tabular}

Table 3. Comparison of Results by Functional Outcomes

\begin{tabular}{|c|c|c|c|c|c|c|}
\hline \multirow{2}{*}{ 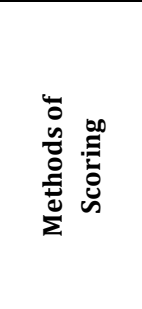 } & \multicolumn{3}{|c|}{$\begin{array}{c}\text { Patients Treated } \\
\text { by ORIF } \\
\text { Mean } \pm \text { S.D. }\end{array}$} & \multicolumn{3}{|c|}{$\begin{array}{c}\text { Patients Treated } \\
\text { Conservatively } \\
\text { Mean } \pm \text { S.D. }\end{array}$} \\
\hline & 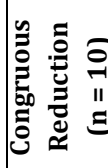 & 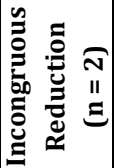 & 2 & 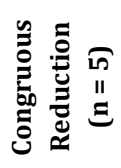 & 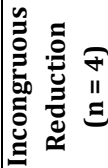 & 2 \\
\hline $\begin{array}{l}\text { Harris' Hip } \\
\text { Score (\%) }\end{array}$ & $\begin{array}{c}89.5 \pm \\
3.24\end{array}$ & $83.0 \pm 0$ & $\mathrm{P}=0.02$ & $\begin{array}{c}82.4 \pm \\
2.70\end{array}$ & $\begin{array}{c}76.25 \pm 4 . \\
03\end{array}$ & $\mathrm{P}=0.03$ \\
\hline $\begin{array}{c}\text { Merle } \\
\text { d'Aubigne- } \\
\text { Postel Score }\end{array}$ & $\begin{array}{c}17.5 \pm \\
1.08\end{array}$ & $15.0 \pm 0$ & $\mathrm{P}=0.01$ & $\begin{array}{c}14.8 \pm \\
1.30\end{array}$ & $\begin{array}{c}12.75 \pm 0 . \\
96\end{array}$ & $\mathrm{P}=0.03$ \\
\hline
\end{tabular}

Table 4. Comparison of Results by Functional Outcomes Between Congruous Reduction and Incongruous Reduction within Patients Treated by ORIF and by Conservative Means 


\begin{tabular}{|c|c|c|c|c|c|c|}
\hline \multirow[b]{2}{*}{ 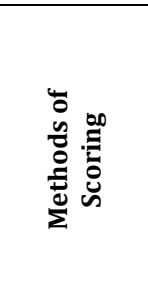 } & \multicolumn{3}{|c|}{$\begin{array}{l}\text { Congruous Reduction } \\
\text { from Both Groups }\end{array}$} & \multicolumn{3}{|c|}{$\begin{array}{l}\text { Incongruous Reduction } \\
\text { from both Groups }\end{array}$} \\
\hline & 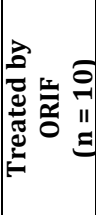 & 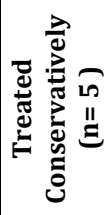 & a & 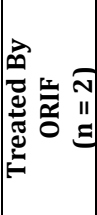 & 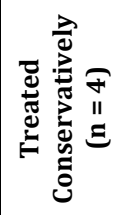 & a \\
\hline $\begin{array}{l}\text { Harris' Hip } \\
\text { Score (\%) }\end{array}$ & $\begin{array}{c}89.5 \pm 3 . \\
24\end{array}$ & $\begin{array}{c}82.4 \pm 2.7 \\
0\end{array}$ & $\mathrm{P}=0.001$ & $\begin{array}{c}83.0 \pm \\
0\end{array}$ & \begin{tabular}{|c|}
$76.25 \pm 4.0$ \\
3
\end{tabular} & $\mathrm{P}=0.089$ \\
\hline $\begin{array}{c}\text { Merle } \\
\text { d'Aubigne- } \\
\text { Postel Score }\end{array}$ & $\begin{array}{c}17.5 \pm 1 \\
08\end{array}$ & $\begin{array}{c}14.8 \pm 1.3 \\
0\end{array}$ & $\mathrm{P}=0.001$ & $\begin{array}{c}15.0 \pm \\
0\end{array}$ & $\begin{array}{c}12.75 \pm 0.9 \\
6\end{array}$ & $\mathrm{P}=0.023$ \\
\hline
\end{tabular}

Table 5. Comparison of Results by Functional Outcomes Between Patients Treated by ORIF and by Conservative Means Within Congruous Reduction and Incongruous Reduction
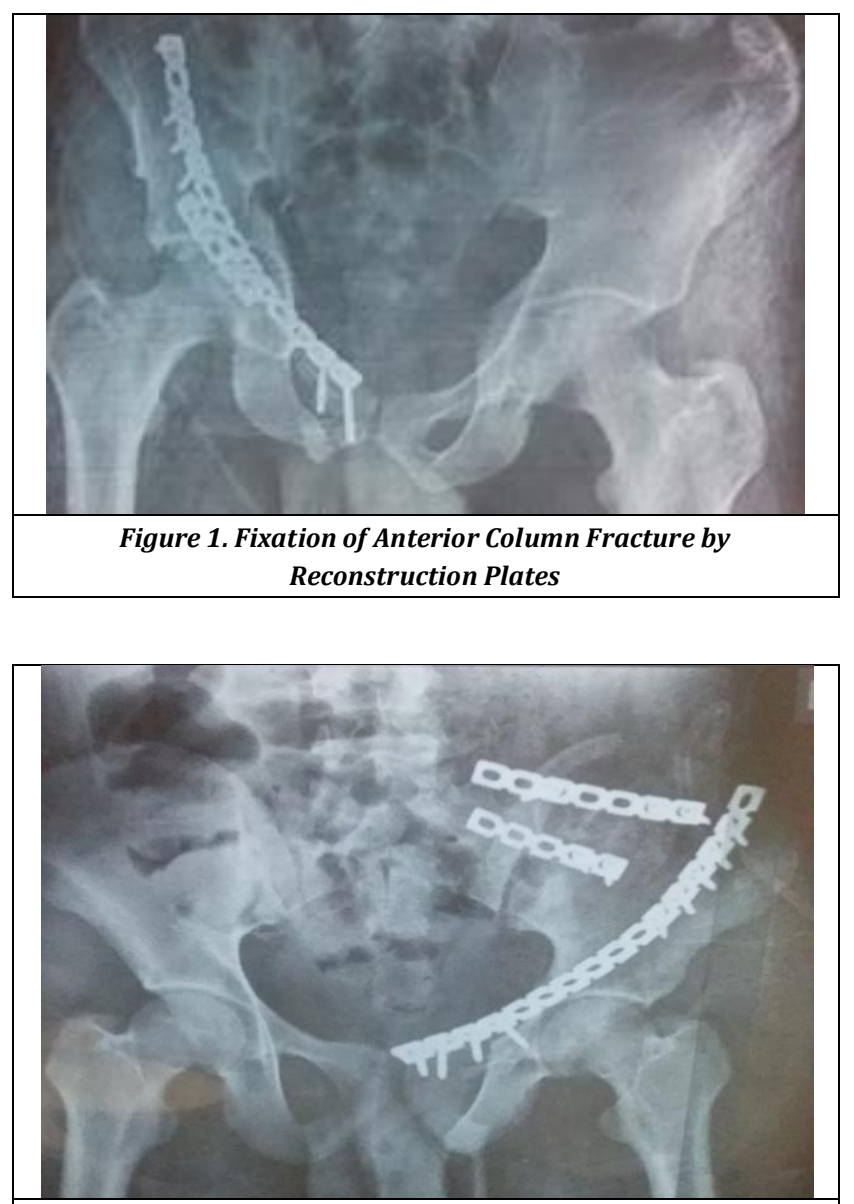

Figure 2. Fixation of Anterior Column Fracture with Sacro-Iliac Joint by Reconstruction Plates

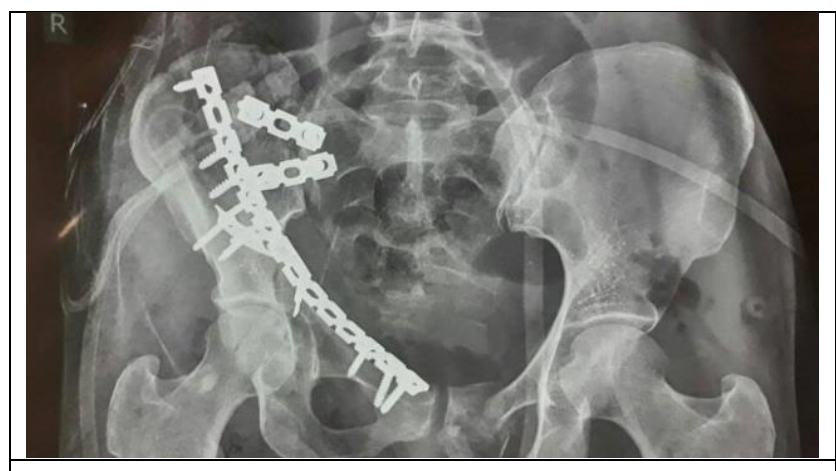

Figure 3. Fixation of the Anterior Column Fracture, Quadrilateral Plate and SI Joint

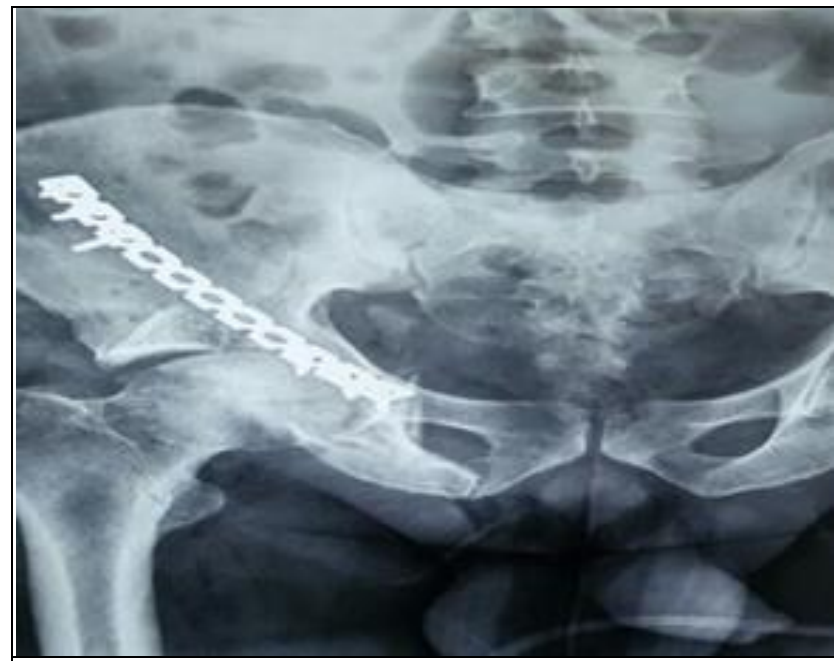

Figure 4. Fixation of Anterior Column Fracture by Reconstruction Plate

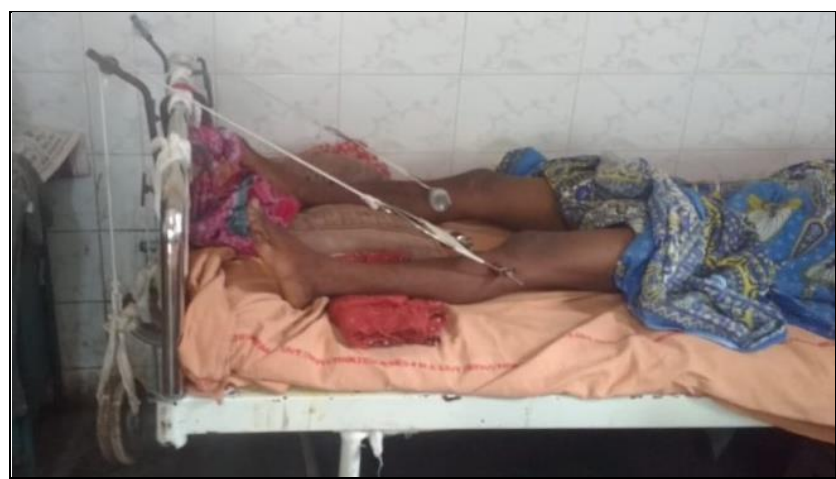

Figure 5. Conservative Management of an Acetabulum Fracture by Bilateral Upper Tibial Traction

\section{Statistical Analysis}

Data were analysed using SPSS (Statistical Package for Social Scientists) version 20.0, IBM, Armonk, New York, USA. Unpaired T-test and Chi-square test were applied at 5\% significance level.

\section{RESULTS}

Results were assessed by radiologic methods as described by Matta. J. (Box 1) and functional methods as described by Harris Hip Score (Annexure-1), and Merle d'Aubigne and Postel (Box-2).

In this study we observed that the patients were from age 29 years to 60 years with maximum incidence between 31 to 40 year age. The mean age for patients in conservatively treated group was 48.33 yrs. \pm 10.74 , and that for patients of ORIF group was 35.6 yrs. \pm 4.14 , with a significant $p$ value of less than 0.001 (Table 2).We also observed that incidence amongst males was 3.2 times more than females, with a $\mathrm{p}$ value of 0.35 (yates correction, Table 2), which is statistically insignificant.

of the 9 patients treated by conservative methods, who followed up, radiological outcome was good in 5 and fair in the rest 4. Harris Hip Score was $79.67 \% \pm 4.5 \%$ (fair to good). Five Patients in this group with congruous reductions had an average HHS of $82.4 \% \pm 2.70 \%$, and the rest 4 who had incongruous reductions had an average HHS of $79.67 \% \pm 4.5 \%$. The overall Merle d'Aubigne-Postel score in this group was $13.89 \pm 1.54$ (The 5 with congruous reductions having a score of $14.8 \pm 1.30$, and the rest 4 having an average of $12.75 \pm 0.96$ ). 
The other group of twelve patients underwent ORIF. In this group, where 10 patients had congruous and 2 had incongruous reduction, radiological outcome was excellent in 8 of the 10 congruent reductions and was good in rest 2 (Table 1). The 2 other patients who had incongruous reduction, had good outcome (Table 1). Overall Harris Hip Score was $88.42 \% \pm 3.87 \%$ in this group of which 10 patients with congruous reduction had a mean HHS of $89.5 \% \pm 3.24 \%$ (Good to excellent) and rest 2 had a mean HHS of $83 \%$ (good). The overall mean MDBP score for the operated group of 12 patients was 17.08 \pm 1.38 (Mean MDBP scores were $17.5 \pm 1.08$ and 15.0 respectively for congruous and incongruous reduction).

The results obtained by radiological outcomes were not compared to ascertain significance of variation as there were some zero results. In this study we observed that there was statistically significant difference, between the groups treated with operative and conservative methods, $\mathrm{P}<0.001$ in both HHS and MDBP scores (Table 3). Comparison of the HHS and MDBP scores in the operated patients with congruous and incongruous reduction, showed that the difference observed was significant, $\mathrm{P}$ $=0.02$ for HHS and $\mathrm{P}=0.03$ for MDBP respectively (Table 4). Again, the same scores observed and compared between the congruous reduction patients and incongruous reduction patients among the conservatively treated patients, was of significant variance, $\mathrm{P}=0.03$ in both the instances (Table 4). We also found on comparing both the HHS and MDBP scores for congruous reduction patients treated by ORIF and those treated conservatively, had a significant variation with $\mathrm{P}=0.001$ (Table 5). The difference of HHS for patients with incongruous reduction treated by ORIF and those treated conservatively had a statistically not so significant value of $\mathrm{P}=0.089$ whereas the difference in MDBP scores in this group being significant, $\mathrm{P}=$ 0.023 (Table 5).

All minimally displaced (Lesser than $3 \mathrm{~mm}$ ) fractures of anterior column treated conservatively showed signs of union. Functional outcome of the patients treated conservatively was good although there was initial stiffness which was overcome by continuous physiotherapy. Union time was approximately 8 weeks in the conservative group and 10 weeks in the operated patients. Infection, mostly superficial complicated the course of $10 \%$ of patients in the operated group, but was manageable by superficial debridement, lavage and antimicrobials. There was no avascular necrosis, or non-union in this study.

\section{DISCUSSION}

Surgeries for management of pelvi-acetabular fractures are gaining popularity with every passing day. Continuous research and studies in this field, has led to the adoption of various methods of approach and solution to the puzzles of the pelvi-acetabular fractures.

In our study we found that patients who underwent conservative methods of treatment with minimal displacement were of a higher age group as compared to the other group, may be due to the lesser activity level, and lower force of trauma.

Though ORIF is the best method of the treatment of pelviacetabular fractures, it is a fact that surgeries of acetabular fractures are technically challenging. The surgical approaches and reduction techniques must be thoroughly understood to properly manage this three-dimensional problem. The complicated anatomy of the acetabular region, frequent severe associated injuries, and long-term complications, all contribute to management difficulties. ${ }^{7}$

In a case report by Dhaniwala NS, Dhaniwala MN, they observed that conservative treatment in form of traction followed up with mobilization of hip can be tried with reasonable functional outcome in undisplaced/minimally displaced fracture acetabulum. ${ }^{8}$ In a study by Magala M et.al, they observed that conservative management can also give good radiological and functional outcomes in congruent reductions. ${ }^{9}$ Sen RK and Veerappa LA in a study observed that conservative treatment continues to be the mainstay of treatment in many centers in developing countries due to lack of infrastructure, and poor availability of skilled services, and also to some extent, due to delayed referrals, economic constraints of patients and patients not consenting to surgery. ${ }^{10}$ Roetman B and others in a study found that conservative treatment is also associated with lesser complications, like iatrogenic nerve palsies, infections, pulmonary embolism, femoral head necrosis, and heterotrophic ossification. These complications, usually follows ORIF, which tend to decline the functional outcome of the fractures, following ORIF, in the long run, in spite of achieving good reduction during surgery. ${ }^{11}$

\section{CONCLUSIONS}

Minimally displaced fractures with lesser than $3 \mathrm{~mm}$ displacement or without stepping, may be treated by conservative methods, but fractures with larger displacements and non-congruent ones should be managed operatively. Expertise of the surgeon and approach to the fracture also influences the outcome.12,13 A larger study, having larger number of patients in both the groups, or multicentric studies are required to have a better understanding of the comparison.

\section{ACKNOWLEDGEMENTS}

We hereby acknowledge Dr. Shuvankar Mukherjee, Assistant Professor of Community Medicine, Calcutta National Medical College, for guiding us through the statistical calculations and analyses.

\section{REFERENCES}

[1] Rowe CR, Lowell JD. Prognosis of fractures of the acetabulum. J Bone Joint Surg Am 1961;43(1):30-92.

[2] Matta JM, Anderson LM, Epstein HC, et al. Fractures of the acetabulum. A retrospective analysis. Clin Orthop Relat Res 1986;(205):230-40.

[3] Tornetta P 3rd, Mostafavi HR. Hip dislocation: current treatment regimens. J Am Acad Orthop Surg 1997;5(1):27-36.

[4] Matta JM. Fractures of the acetabulum: accuracy of reduction and clinical results in patients managed operatively within three weeks after the injury. J Bone Joint Surg Am 1996;78(11):1632-45.

[5] Harris WH. Traumatic arthritis of the hip after dislocation and acetabular fractures: treatment by mold arthroplasty. An end-result study using a new method of result evaluation. J Bone Joint Surg (Am) 1969;51(4):737-55.

[6] d'Aubigne RM, Postel M. Function al results of hip arthroplasty with acrylic prosthesis. J Bone Joint Surg (Am) 1954;36-A(3):451-75. 
[7] Hofmann AA, Dahl CP, Wyatt RW. Experience with acetabular fractures. J Trauma 1984;24(8):750-2.

[8] Dhaniwala NS, Dhaniwala MN. Conservative management of acetabular fractures-case reports. MOJ Orthop Rheumatol 2018;10(3):329-31.

[9] Magala M, Popelka V, Božík M, et al. Conservative treatment of acetabular fractures: epidemiology and medium-term clinical and radiological results. [Article in Slovak]. Acta Chir Orthop Traumatol Cech 2015;82(1):51-60.

[10] Sen RK, Veerappa LA. Long-term outcome of conservatively managed displaced acetabular fractures. J Trauma 2009;67(1):155-9.
[11] Roetman B, Seybold D, Keil D, et al. Long-term results after acetabular fractures with respect to heterotopic ossifications. Zentrabl Chir 2006;131(3):188-93.

[12] Glas PY, Fessy MH, Carret JP, et al. Surgical treatment of acetabular fractures: outcome in a series of 60 consecutive cases. Rev Chir Orthop Reparatrice Appar Mot 2001;87(6):529-38.

[13] Giannoudis PV, Bircher M, Pohlemann T. Advances in pelvic and acetabular surgery. Injury 2007;38(4):3956. 